\title{
Research Paper Robust modeling in the presence of outliers for food grain production in India
}

\section{Sunali Mahajan, Manish Sharma and Banti Kumar}

See end of the paper for authors' affiliations

Correspondence to :

Sunali Mahajan

Division of Statistics and

Computer Science,

Sher-e-Kashmir University of Agricultural Sciences and Technology of Jammu, Jammu (J\&K) India Email : sunali12mahajan @gmail.com

Paper History :

Received : 28.04.2017;

Revised : 04.01.2018

Accepted : 18.01 .2018
ABSTRACT : The traditional ordinary least squares procedure (OLS) is the most frequently used method for analyzing food grain production data (1983-2014), but ignore the presence of outliers or influential data points which may distort the regression estimates obtained from OLS. These data points may remain unnoticed and can have a strong adverse affect on the regression estimates. In this paper, two approaches i.e., robust M-regression and quantile regression to linear robust regression analysis are presented, as these methods provide formal procedure to overcome from the situation of outliers and influential observations and to reduce their influence on the final estimates of the regression co-efficients by using Cobb-Douglas production function. Moreover, $0.90^{\text {th }}$ quantile regression model comes out to be best on the basis of AIC (-47.17), SBIC (-36.91), elasticity of production, marginal value productivity, sign, size and the variables significant effect on foodgrain production than OLS and robust M-regression. Also, the variables NSA and AC were best in order to increase the food grain production on the basis of quantile $0.90^{\text {th }}$ regression, elasticity of production and MVP at $0.90^{\text {th }}$ quantile.

Key WordS : Ordinary least square, Outliers, Robust regression, Quantile regression, M-estimator, Food grain production

How To Cite This PAPer : Mahajan, Sunali, Sharma, Manish and Kumar, Banti (2018). Robust modeling in the presence of outliers for food grain production in India. Internat. Res. J. Agric. Eco. \& Stat., 9 (1) : 25-30, DOI : 10.15740/HAS/IRJAES/9.1/25-30. 